\title{
COMUNICAÇÃO
}

\section{USO DE TÁRTARO EMÉTICO TÓPICO NA LEISHMANIOSE CUTÂNEA}

\author{
Gustavo A.S. Romero, Julia S.A. Vela e Philip D. Marsden
}

Durante o desenvolvimento de um estudo terapêutico para avaliar a eficácia do sulfato de aminosidine na leishmaniose mucosa causada por Leishmania (Viannia) braziliensis (L(V)b), na área endêmica de Corte de Pedra ${ }^{i}$, foi tratado um paciente masculino de 64 anos (LTCP 10065) originário e residente em uma fazenda do município de Piraí do Norte cuja queixa principal foi obstrução nasal e epistaxe de quatro meses de evolução. Diagnosticou-se a leishmaniose mucosa com base nos achados clínicos, imunológicos (intradermorreação de Montenegro de $15 \mathrm{~mm}$ e título na reação de imunofluorescência indireta para anticorpos séricos antileishmânia de $1 / 64$ ) e o estudo histopatológico da biópsia da mucosa atingida que revelou um padrão compatível com leishmaniose e ausência de parasitos. A inoculação de material de biópsia em hamsters teve resultado negativo. O paciente foi tratado com sulfato de aminosidine, $16 \mathrm{mg} / \mathrm{kg} /$ dia por 20 dias, considerando-se clinicamente curado $u \mathrm{~m}$ ano após tratamento. Como único antecedente relevante para a doença atual, 30 anos antes, tinha desenvolvido três úlceras cutâneas nos antebraços. Estas lesões foram tratadas com pó de tártaro emético em forma tópica que o paciente comprou na farmácia local sem prescrição médica. As lesões curaram em 40 dias e deixaram cicatrizes típicas de leishmaniose de 15,18 e $20 \mathrm{~mm}$ de diâmetro.

O tártaro emético foi utilizado pela primeira vez no tratamento da leishmaniose tegumentar americana por Gaspar Vianna em 19125, iniciando-se assim a era do tratamento desta doença com antimoniais. Porém, o uso tópico deste medicamento de comprovada eficácia por via sistêmica mas de elevada toxicidade tem sido raramente descrito. Durante um surto epidêmico de leishmaniose cutânea na Guiana, o tártaro emético foi relatado entre os agentes tópicos utilizados pelos pacientes antes da consulta descrevendo-se piora das lesões ${ }^{3}$. No caso aqui relatado, as três úlceras cicatrizaram

Núcleo de Medicina Tropical, Universidade de Brasília, Brasília, DF

Recebido para publicação em 26/01/96. aproximadamente em sete semanas quando a maioria das úlceras por L(V)b, nesta área endêmica, cicatriza no período entre 12 e 20 semanas após tratamento sistêmico com antimonial pentavalente ${ }^{2}$, achado que poderia sugerir algum efeito leishmanicida do tártaro emético. Em Corte de Pedra, a população utiliza vários agentes tópicos sem eficácia comprovada para o tratamento da leishmaniose cutânea porém, nunca se tinha relatado o uso de tártaro emético tópico para este fim. Embora os antimoniais pentavalentes tenham sido utilizados por várias décadas por via sistêmica para o tratamento das leishmanioses, até o momento não existem dados defintivos sobre a sua potencialidade para uso tópico.

\section{REFERÊNCIAS BIBLIOGRÁFICAS}

1. França F, Lago EL, Tada S, Costa JML, Vale K, Oliveira J, Costa MA, Osaki M, Cheever L, Netto EM, Barreto AC, Johnson WD, Marsden PD. An outbreak of human Leishmania (Viannia) braziliensis infection. Memórias do Instituto Oswaldo Cruz 86:169-174, 1991.

2. Llanos-Cuentas EA, Marsden PD, Lago EL, Barreto AC, Cuba CC, Johnson WD. Human mucocutaneous leishmaniasis in Três Braços, Bahia-Brazil. An area of Leishmania braziliensis braziliensis transmission II. Cutaneous disease presentation and evolution. Revista da Sociedade Brasileira de Medicina Tropical 17:169-177, 1984.

3. Low-A-Chee RM, Rose P, Ridley DS. An outbreak of cutaneous leishmaniasis in Guyana: epidemiology, clinical and laboratory aspects. Annals of Tropical Medicine and Parasitology 77:255-260, 1983.

4. Netto EM,Tada MS, Golightly L, Kalter DC, Lago E, Barreto AC, Marsden PD. Conceitos de uma população local a respeito de leishmaniose mucocutânea em uma área endêmica. Revista da Sociedade Brasileira de Medicina Tropical 18:3337,1985

5. Vianna G.Tratamento da leishmaniose tegumentar por injeções intravenosas de tartaro emético. In: Annais do $7^{\circ}$ Congresso Brasileiro de Medicina e Cirurgia 4:426-428, 1912. 